\title{
Los libros de arquitectura en la Valencia del siglo XVIII: de los modelos del Barroco a la Academia de San Carlos ${ }^{1}$
}

\author{
Pablo González TORnel \\ UNIVERSITAT JAUME I (CASTELLÓN)
}

\begin{abstract}
Books of architecture in Valencia during the XVIIIth Century: from the Baroque models to the Academy of San Carlos
\end{abstract}

\begin{abstract}
RESUMEN
El presente artículo estudia el impacto de la circulación de libros y estampas sobre arquitectura, perspectiva o arqueología sobre la construcción en Valencia durante el siglo XVIII. Se analizan para ello los inventarios en los que estas obras impresas se documentan y se cotejan las mismas con las obras efectivamente edificadas, buscando los modelos estructurales y decorativos empleados por los arquitectos.
\end{abstract}

PALABRAS CLAVE: Barroco, Academia, Valencia, libro de arquitectura.

\begin{abstract}
This essay studies the impact of books and prints of architecture, perspective or archaeology on the construction in Valencia during the 18th century. It analyzes the mention of some of these books in documents and compares them with the constructions built in the city looking for the structural and decorative models used by the architects.
\end{abstract}

KEYWORDS:

Baroque, Academy, Valencia, book of architecture.

En 1701, con motivo de la celebración del concurso de proyectos para la realización de la fachada principal de la Catedral de Valencia, Juan Pérez Artigues, un presbítero valenciano, dejaba por escrito un encendido ataque a los presentados por los maestros Francisco Padilla y Conrad Rudolph. En su texto, apoyando la defensa de la propuesta de su padre, el arquitecto Juan Pérez Castiel, se empleaba, por primera vez en la arquitectura barroca valenciana, la auctoritas como justificación teórica de una determinada opción arquitectónica, y se enumeraba una serie de tratados europeos como base sólida de la arquitectura de la ciudad, en concreto

1 La reproducción de la mayoría de los grabados que ilustran este artículo ha sido posible gracias a la colaboración de la Biblioteca de la Real Academia de Bellas Artes de San Carlos y del Servei de Biblioteques i Documentació de la Universitat de València, donde se encuentra depositados los documentos originales. 
las obras de Vitrubio, Alberti, Serlio, Vignola, Palladio², Fray Lorenzo de San Nicolás ${ }^{3}$, Juan Caramuel de Lobkowitz ${ }^{4}$ y Andrea Pozzo ${ }^{5}$.

En 1767 se realizaba el inventario de la biblioteca de la institución que, en las décadas sucesivas, se erigiría en depositaria del conocimiento arquitectónico del reino y ejercería un férreo control sobre toda construcción de envergadura, la Real Academia de Bellas Artes de San Carlos.

El siglo XVIII se abría, de este modo, dando inicio a la gran estación de la arquitectura barroca valenciana y marcando, a través de las cultas citas de Juan Pérez Artigues, una tendencia aperturista y cosmopolita de muchos maestros de obras. El inventario de 1767 sancionaba la figura del arquitecto de formación intelectual y marcaba, al mismo tiempo, el despegue del Academicismo en la arquitectura valenciana. Ambos momentos marcan dos hitos de un interesantísimo período de superación de las tendencias un tanto localistas del siglo XVII que se nutre, muchas veces, del estímulo de la cultura libresca cuya presencia, a través de la documentación o de las propias obras construidas, pretende analizarse en el presente estudio.

\section{LA PRIMERA MITAD DEL SIGLO XVIII: LA ARQUITECTURA ESPECULATIVA Y LA BÚSQUEDA DE MODELOS}

El peso de algunas de las obras enumeradas por Juan Pérez Artigues en 1701 sobre la arquitectura construida en la ciudad de Valencia y su entorno es perfectamente constatable y, en algunos casos, un factor fundamental en la concreción de las maneras arquitectónicas de los maestros de mayor renombre. En particular resulta abrumadora la importancia de la Arquitectura Civil Recta y Oblicua del obispo de Vigévano Juan Caramuel que, mediante distintas aplicaciones de sus propuestas, extiende su influencia casi desde el momento de su publicación, en 1678, hasta los inicios de la actividad de la Academia.

Caramuel había planteado una distinción entre arquitectura recta y oblicua que se centra en el carácter de plantas y alzados ${ }^{6}$. La arquitectura recta sería aquella que se ciñe a la ortogonalidad en ambos ámbitos de manera que los muros se encuentran siempre en ángulo recto. La arquitectura oblicua, por el contrario, se caracterizaría por la no ortogonalidad en alzado, en planta, o en ambos. Esta no or-

\footnotetext{
${ }^{2}$ No existe modo de conocer, por el momento, a qué ediciones de estas obras se refiere Juan Pérez Artigues.

3 SAN NICOLÁS, FRAY LORENZO DE: Arte y uso de arquitectura. Madrid, 1639 y 1665.

${ }^{4}$ CARAMUEL DE LOBKOWITZ, JUAN: Architectura ciuil recta y obliqua: considerada y dibuxada en el templo de lerusalen. Vigévano, por Camillo Corrado, 1678.

5 POZZO, ANDREA: Perspectiva pictorum et architectorum. Roma, por Giovanni Giacomo Komarek, 1693-1700.

${ }^{6}$ CARAMUEL DE LOBKOWITZ, JUAN: op. cit., Tratado V. En que se enseña la Architectura Recta, p. 30.
} 
togonalidad aparece planteada con muchas posibilidades de variación y combinatoria, ya que las plantas de los edificios no ortogonales pueden serlo por la curvatura de los muros o porque los encuentros entre ellos no se realicen en ángulo recto, oblicuidad Ilamada declinación por Caramuel7. Por otro lado, en alzado, la oblicuidad se produciría por inclinación ${ }^{8}$, al asentarse los muros sobre superficies no horizontales.

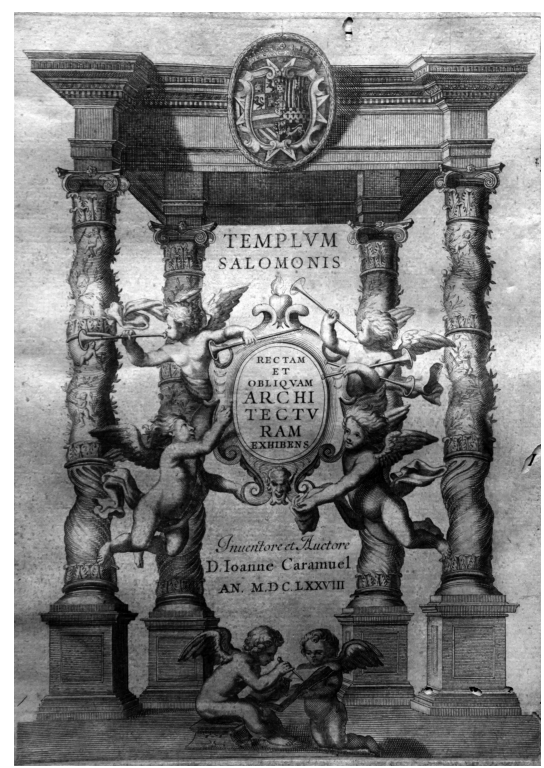

Figura 1. Frontispicio de CARAMUEL DE LOBKOWITZ, JUAN: Architectura civil recta y obliqua: considerada y dibuxada en el templo de lerusalen. Vigévano, por Camillo Corrado, 1678. Biblioteca Histórica de la Universitat de València. Fotografía del autor.

La aplicación de los principios de Caramuel produciría en la arquitectura no ortogonal, según el autor, la aceptación de la oblicuidad en planta o alzado y el sometimiento de todos sus miembros, bóvedas, columnas y pilastra, muros y decoración, a las deformaciones planteadas por la geometría irregular del edificio. Es decir, todos los componentes de la obra arquitectónica deben curvarse, declinarse o inclinarse cuando la morfología de la estructura de la que forman parte así lo requiera.

La más temprana aplicación de los principios de la arquitectura oblicua en Valencia aparece de la mano de Joan Blai Aparisi, quien en la Colegiata de Xàtiva inclina y curva todos los elementos arquitectónicos de las fachadas del crucero

7 CARAMUEL DE LOBKOWITZ, JUAN: op. cit., Tratado VI. En que se enseña la Architectura Obliqua, p. 5.

8 CARAMUEL DE LOBKOWITZ, JUAN: op. cit., Tratado VI. En que se enseña la Architectura Obliqua, p. 6. 
para adaptar el lenguaje clásico a superficies no horizontales ${ }^{9}$, aportación que incluirá también en su proyecto no realizado para el nuevo puente de piedra sobre el río Segura en Murcia ${ }^{10}$.

Sin embargo, la obra en la que mejor cristaliza el profundo estudio de la obra de Caramuel por parte de Aparisi es en la reforma del monasterio cisterciense de Santa María de la Valldigna, cerca de Gandía, proyectada por el maestro en $1687^{11}$.

La arquitectura oblicua era sólo uno de los componentes de la teoría del obispo de Vigévano quien, desde el propio título de su tratado, proponía como modelo absoluto para la construcción moderna el Templo de Salomón. Y así, en la enorme iglesia de la Valldigna, junto a la presencia de las pinturas, pilastras, entablamentos y decoraciones oblicuas, se realiza una recuperación del Templo de Jerusalén como modelo de la arquitectura religiosa occidental en la que todos los elementos de la reconstrucción formulada por Caramuel aparecen puntualmente reflejados. Desde el nártex con paños color carmesí o la decoración de querubines, hasta el baldaquino del altar mayor o el sancta sanctorum cuajado de elementos oblicuos $^{12}$.

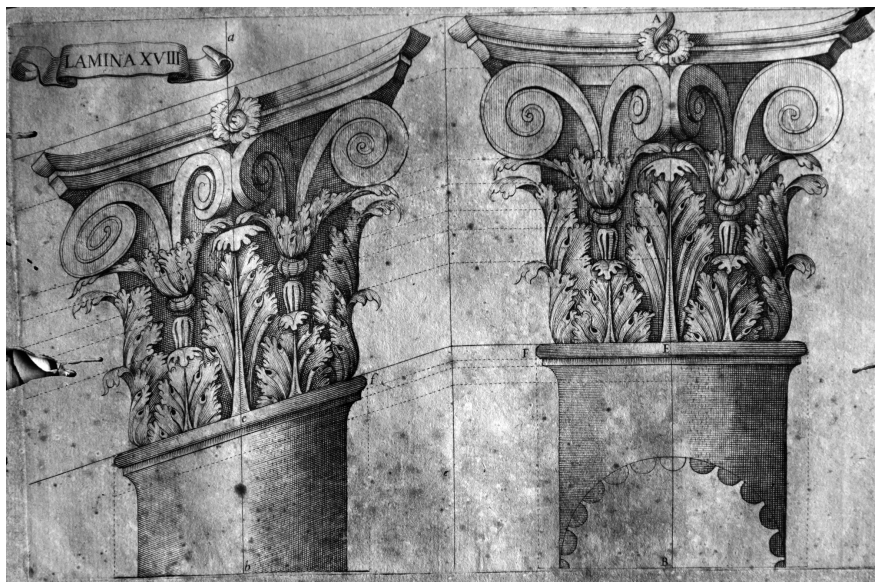

Figura 2. CARAMUEL DE LOBKOWITZ, JUAN: Architectura civil recta y obliqua: considerada y dibuxada en el templo de lerusalen. Vigévano, por Camillo Corrado, 1678. Lámina XVIII de la Architectura Oblicua. Biblioteca Histórica de la Universitat de València. Fotografía del autor.

9 VILAPLANA ZURITA, DAVID: «Influencias del tratado de Caramuel en la arquitectura de la Colegiata de Xàtiva». Archivo de Arte Valenciano, 66, (1985), pp. 61-63. Véase al respecto también BÉRCHEZ, JOAQUÍN Y GÓMEZ-FERRER, MERCEDES: La Seo de Xàtiva. Valencia, Generalitat Valenciana, 2007, pp. 67-85.

10 DE LA PEÑA VELASCO, CONCEPCIÓN: El puente viejo de Murcia. Murcia, Universidad de Murcia, 2001, pp. 68-84.

${ }_{11}$ La paternidad de Aparisi se documenta en la subasta de las obras: Archivo del Reino de Valencia (A.R.V.), notario Francisco Martí, signatura 1369, 13 de abril de 1687, s/f.

12 Véase GONZÁLEZ TORNEL, PABLO: «El templo cisterciense de Santa María de la Valldigna. La arquitectura oblicua de Juan Caramuel, la evocación de San Pedro del Vaticano y el Templo de Salomón», Goya, (en prensa). 


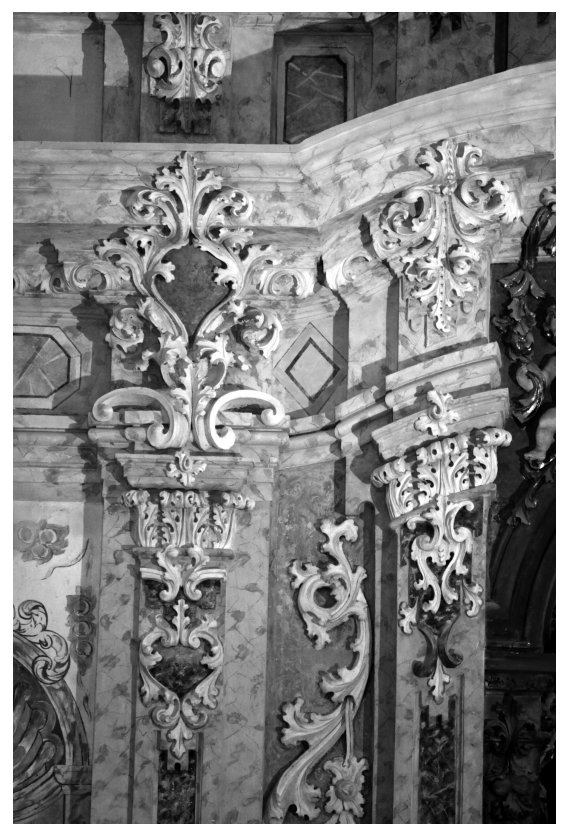

Figura 3. Iglesia conventual de Santa María de la Valldigna (Valencia). Detalle de la articulación oblicua de la cabecera. Fotografía del autor.

Una interpretación diferente del texto de Caramuel sería emprendida, casi medio siglo después, por el maestro de obras José Mínguez en el templo del Colegio de San Pío V de Valencia ${ }^{13}$.

En San Pío V se formulaba una planta octogonal con deambulatorio que resultaba de la combinación de la estampa publicada por Antonio Labacco sobre el proyecto de Antonio da Sangallo para San Giovanni dei Fiorentini ${ }^{14}$, incluida por Caramuel en su tratado como una ideación propia ${ }^{15}$, con la planta del baptisterio de San Juan de Letrán, impresa en la lámina LVII de la Architectura Recta como ejemplo ofrecido por el obispo de Vigévano de la incorrecta aplicación de los principios de la arquitectura oblicua. Pero, además del empleo por parte de José Mínguez de dos modelos gráficos directamente extraídos de la obra de Caramuel, la obra de la iglesia octogonal muestra un profundo entendimiento de los principios de la arquitectura oblicua. La generatriz octogonal del templo es empleada por el arquitecto

13 GONZÁLEZ TORNEL, PABLO: «La iglesia octogonal del Colegio de San Pío V y el arquitecto José Mínguez», Boletín del Museo e Instituto Camón Aznar, 104, (2009), pp. 167-210. Véanse también GONZÁLEZ TORNEL, PABLO: «José Mínguez. Un arquitecto barroco en la Valencia de la primera mitad del siglo XVIII». Goya, 332, (2010), pp. 212-228, GONZÁLEZ TORNEL, PABLO: José Mínguez. Un arquitecto barroco en la Valencia del siglo XVIII, Castellón, Universitat Jaume I, 2010.

${ }_{14}$ LABACCO, ANTONIO: Libro d'Antonio Labbaco appartenente a l'architettura nel qual si figurano alcune notabili antiquita di Roma. Roma, a casa nostra, 1559, Tablas 26, 27 y 28.

15 CARAMUEL DE LOBKOWITZ, JUAN: op. cit., láminas XXVI y XXVII de la Architectura Obliqua. 
para someter a su dictado todos los elementos constructivos del mismo. Así, los machones que soportan la cúpula, al igual que sus correspondientes en el perímetro del deambulatorio, tienen una curiosa planta triangular con sus extremos interior cóncavo y exterior convexo, los cuales generan la conversión de las pilastras en lesenas angulares cóncavas y convexas. En consecuencia, y por coherencia constructiva y geométrica, los arcos tendidos entre los machones del octógono interior y los del exterior, que soportan las bóvedas trapezoidales del deambulatorio, están generados a partir de una compleja torsión, cuya dificultad se acentúa al apoyar en soportes desiguales. Estos arcos, para adecuarse a las pilastras angulares convexas del octógono interno y a las cóncavas del externo, degeneran conforme se alejan del centro geométrico del templo desde la forma angular convexa a la cóncava. Todos y cada uno de los elementos constructivos y compositivos del doble octógono de San Pío V responden, de esta manera, a la perfección a los postulados de Juan Caramuel y son, hasta el último de ellos, correctamente declinados según los principios de la arquitectura oblicua.

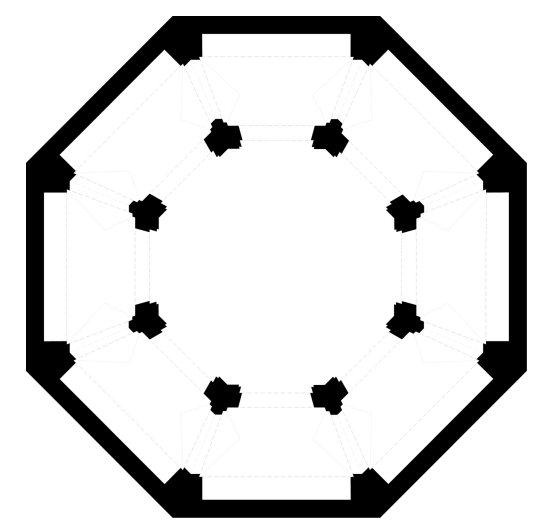

Figura 4. Planta de la iglesia del Colegio-Seminario de San Pío V (Valencia). Dibujo del autor.

La segunda de las obras citadas por Juan Pérez Artigues que demostraría una notable incidencia durante la primera mitad del siglo XVIII es el tratado de perspectiva de Andrea Pozzo, y su riquísimo conjunto de láminas sería fundamental en la evolución de la concepción del retablo en Valencia. Sin embargo, la práctica desaparición de la totalidad de este tipo de estructuras obliga a indagar su influencia a través de fuentes impresas ${ }^{16}$. En el libro de fiestas publicado con motivo de la celebración del Quinto Centenario de la Conquista en 1738, enriquecido con numerosas estampas de las estructuras efímeras erigidas para la ocasión ${ }^{17}$, aunque mu-

${ }^{16}$ Véase MÍNGUEZ, VÍCTOR; GONZÁLEZ TORNEL, PABLO; RODRÍGUEZ MOYA, INMACULADA: La Fiesta Barroca. El Reino de Valencia. Castellón, Universitat Jaume I, 2010.

17 ORTÍ Y MAYOR, J. V.: Fiestas centenarias con que la insigne, noble, leal y coronada ciudad de Valencia celebró en su dia 9 de Octubre de 1738, la quinta centuria de su Christiana Conquista. Valencia, por Antonio Bordázar, 1740. Véase MíNGUEZ, VícTOR: Art i arquitectura efímera a la València del S. XVIII. Valencia, Alfons el Magnànim, 1990. 
Los libros de arquitectura en la Valencia del siglo XVIII: de los modelos del Barroco...

chos de los altares construidos mantienen la estructura de graderío piramidal de nulo interés arquitectónico, varios retablos son verdadera imagen de la práctica de la arquitectura en la primera mitad del siglo XVIII. Así ocurre con el altar erigido por los Trinitarios descalzos, obra del pintor Esteban Romaguera, el del convento de Santo Domingo, del dorador Carlos Consergues, el del Colegio de San Pablo, el del convento del Socorro, también diseñado por un pintor, el de la casa profesa de los Jesuitas, el de la parroquia de los Santos Juanes, obra del pintor Francisco Llácer, y el de la parroquia de San Nicolás, diseñado por el grabador José Fortea.

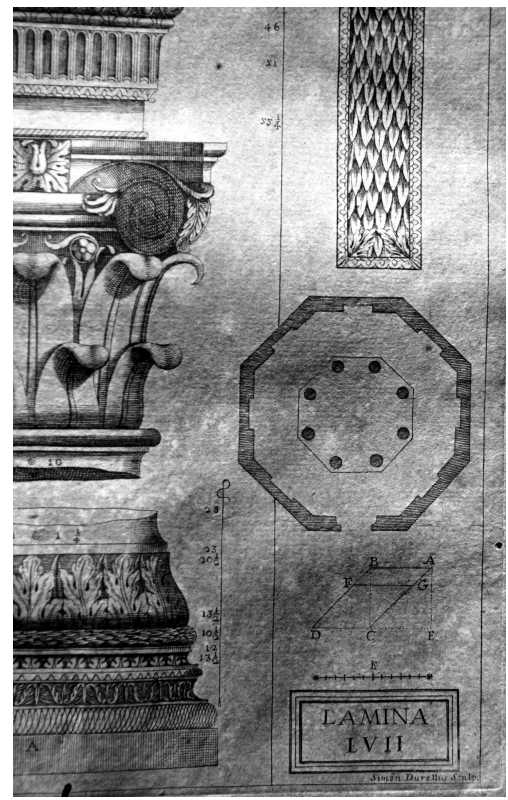

Figura 5. CARAMUEL DE LOBKOWITZ, JUAN: Architectura civil recta y obliqua: considerada y dibuxada en el templo de lerusalen, Vigévano. por Camillo Corrado, 1678. Lámina LVII de la Architectura Recta. Detalle con la planta del Baptisterio de San Juan de Letrán. Biblioteca Histórica de la Universitat de València. Fotografía del autor.

Los puntos de contacto con las láminas del tratado de Pozzo son muchos. Así, por ejemplo, altares como el de Santos Juanes o el de los Trinitarios descalzos albergan una gran hornacina en el cuerpo principal que obliga al artista a incurvar el entablamento de para adecuarse a la curva del vano. Esta flexibilización de las líneas arquitectónicas es planteada por Pozzo, entre otras, en la figura 73 de la segunda parte de su tratado sobre perspectiva, y será retomado muchos años después por Antonio Gilabert para intervenir en la Catedral de Valencia ${ }^{18}$. También del Perspectiva pictorum, en concreto de la segunda lámina de la segunda parte, se extrae el arco en forma de voluta que remata el altar del convento de Santo Domingo.

18 BÉRCHEZ, JOAQUín: Los comienzos de la arquitectura académica en Valencia: Antonio Gilabert., Valencia, Federico Doménech, 1987, pp. 97-158. 


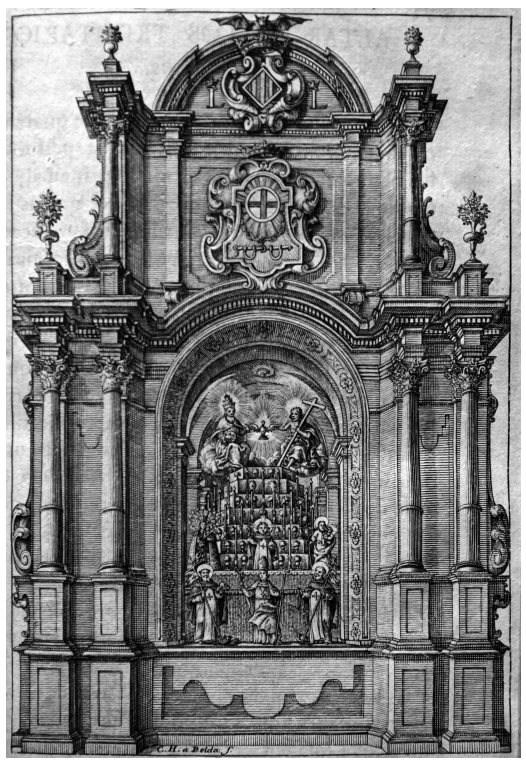

Figura 6. Altar del convento de Trinitarios. En ORTI Y MAYOR, J. V.: Fiestas centenarias con que la insigne, noble, leal y coronada ciudad de Valencia celebró en su dia 9 de Octubre de 1738, la quinta centuria de su Christiana Conquista. Valencia, por Antonio Bordázar, 1740. Biblioteca Histórica de la Universitat de València. Fotografía del autor.

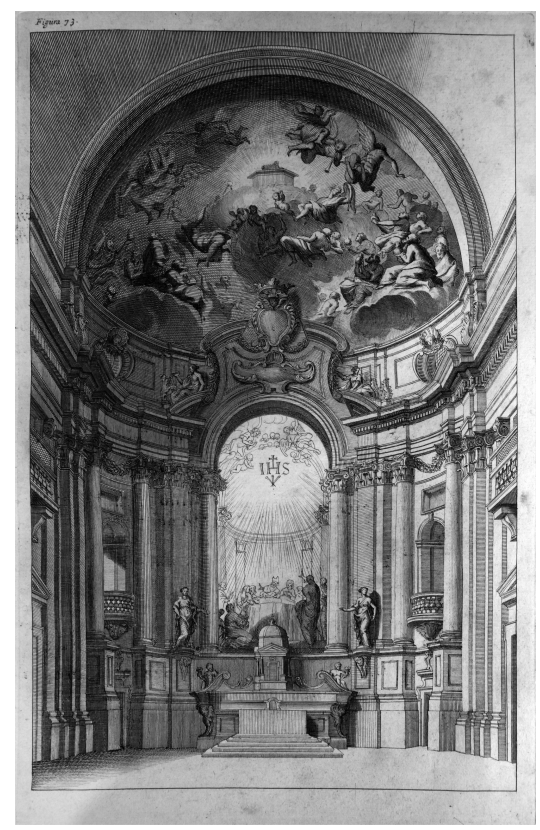

Figura 7. Lámina 73 del primer tomo de POZZO, ANDREA: Perspectiva pictorum et architectorum. Roma, por Giovanni Giacomo Komarek, 1693-1700. Biblioteca de la Real Academia de San Carlos de Valencia. Fotografía del autor. 
Los libros de arquitectura en la Valencia del siglo XVIII: de los modelos del Barroco...

La tendencia a composiciones monumentales, con predominio de los soportes volumétricos y con cultas citas cosmopolitas alcanza su culminación en dos celebraciones muy cercanas en el tiempo. Las fiestas por la proclamación de Carlos III en $1759^{19}$ y las exequias de su esposa Maria Amalia de Sajonia en $1760^{20}$.

De los festejos de 1759 dedicados a Carlos III se grabó, entre otros decorados, el magnífico altar que fue erigido en la plaza de la Virgen por el pintor Carlos Francia. La construcción efímera, tras un jardín con representaciones de los ríos $\mathrm{Pa}$ lancia, Turia, Júcar y Mijares, se estructura como un retablo religioso alrededor de la hornacina central con la estatua ecuestre del monarca. Esta calle principal se remata en arco de gran altura que invade y anula el entablamento, mientras que las laterales, enmarcadas por sólidas columnas de orden compuesto sobre pedestales, se rematan con frontón triangular. Pero los dos elementos que hacen de este retablo algo único en el medio valenciano son, por un lado, el riquísimo ático, y por otro, la planta convexa que hace que la calle central se proyecte y las laterales se incurven retranqueándose. El modelo del ático, cuajado de elementos textiles, heráldicos y figurativos, vuelve a ser Pozzo, quien en obras realizadas y grabadas, como el altar de San Luis Gonzaga en el Colegio Romano, plantea esta suerte de remates en el que los frontones quebrados y las cornisas mixtilíneas se entremezclan con volutas multiplicando los planos de profundidad y creando efectos de gran riqueza. La planta curvilínea, también presente en la obra de Pozzo, tiene, sin embargo, un precedente claro en la propia ciudad de Valencia, la portada cóncavo convexa de la Catedral que, comenzada en 1703, aún ultimaba sus retoques en los momentos de la proclamación de Carlos III21.

Por su parte, el catafalco de Maria Amalia de Sajonia, de autor desconocido y grabado por Manuel Monfort, presenta similitudes con el altar de Carlos Francia aunque el tono de la ornamentación es mucho más contenido. La estructura resulta la habitual de dos cuerpos superpuestos y los detalles compositivos como los arcos invadiendo el entablamento, en este caso el frontón del segundo cuerpo, conducen de nuevo a Pozzo. La estructura recuerda a la perspectiva ofrecida por el italiano en la Figura 71 del primer tomo del Perspectiva Pictorum, donde el remate adquiere la misma forma bulbosa que en el catafalco valenciano. Pero el punto de mayor originalidad del túmulo de Maria Amalia de Sajonia es la inclusión, en los ángulos, de verdaderos arbotantes para soportar los empujes del baldaquino central. Estos arbotantes se configuran como estructuras arquitrabadas transparentes, compuestas por un entablamento continuo apoyado en pilares con semicolumnas

19 OLLER Y BONO, MAURO ANTONIO: Proclamación del Rey Nuestro Señor Don Carlos III (que Dios guarde) en su fidelísima ciudad de Valencia, presentada al publico en esta memoria por Don Mauro Antonio Oller y Bono, regidor perpetuo de esta ciudad, y su comisario en las fiestas. Valencia, por la viuda de Joseph de Orga, 1759.

20 SEGUER, FELIPE: Elogio fúnebre de la sereníssima Maria Amalia de Saxonia que en las reales exequias celebró la ciudad de Valencia en la Santa Metropolitana Iglesia dia 12 de diciembre 1760. Valencia, por Thomás Santos, 1760.

21 PINGARRÓN, FERNANDO: La frontera barroca de la Catedral de Valencia. Valencia, Real Academia de Cultura Valenciana, 1998. 
adosadas. Se configuran así aspas angulares en este monumento que se proyectan hacia el espectador y multiplican las perspectivas del mismo. La idea general de la composición puede relacionarse con la Figura 43 del segundo tomo del Perspectiva Pictorum, en la que se proporciona el dibujo en perspectiva de un edificio centralizado con un cuerpo central arcuado entre dos cuerpos laterales proyectantes.

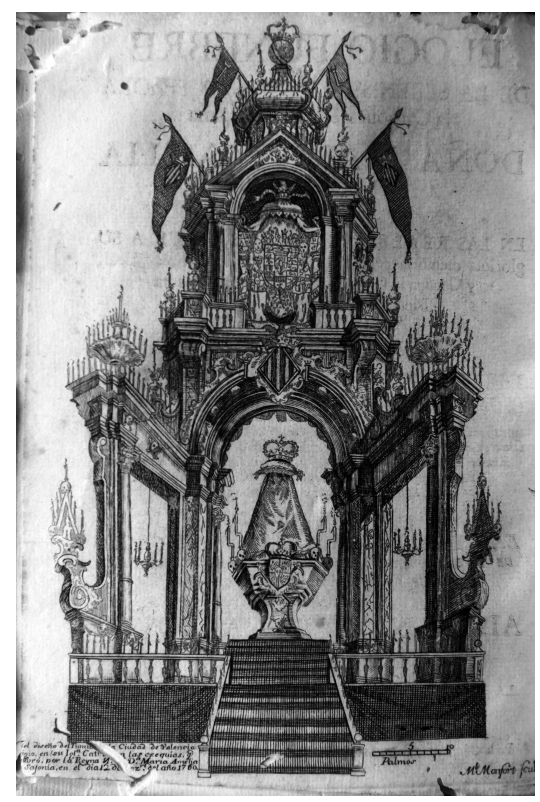

Figura 8. Catafalco de Maria Amalia de Sajonia. En SEGUER, FELIPE: Elogio fúnebre de la sereníssima Maria Amalia de Saxonia que en las reales exequias celebró la ciudad de Valencia en la Santa Metropolitana Iglesia dia 12 de diciembre 1760. Valencia, por Thomás Santos, 1760. Biblioteca Histórica de la Universitat de València. Fotografía del autor.

Pero las vías de experimentación de la arquitectura valenciana durante la primera mitad del siglo XVIII, tendentes al aperturismo de la tradición autóctona hacia visiones más cosmopolitas, no se agotan en la aplicación de la teoría de Juan Caramuel por parte de un reducido grupo de arquitectos o en la confección de retablos siguiendo las escenográficas propuestas de Andrea Pozzo, sino que, en una empresa de mucho mayor calado, tratarán de fijar una nueva tipología para las construcciones eclesiásticas que se inspirará directamente, al menos desde el punto de vista de sus proyectistas, en la mejor arquitectura romana de la Edad Moderna.

Para entender la fijación de esta nueva tipología templaria, que se quiere diferenciada de la tradición local, novedosa, cosmopolita y romana, es necesario hacer referencia a la elección de los proyectos para dos de los templos que contribuirían de manera decisiva al éxito de la propuesta. 


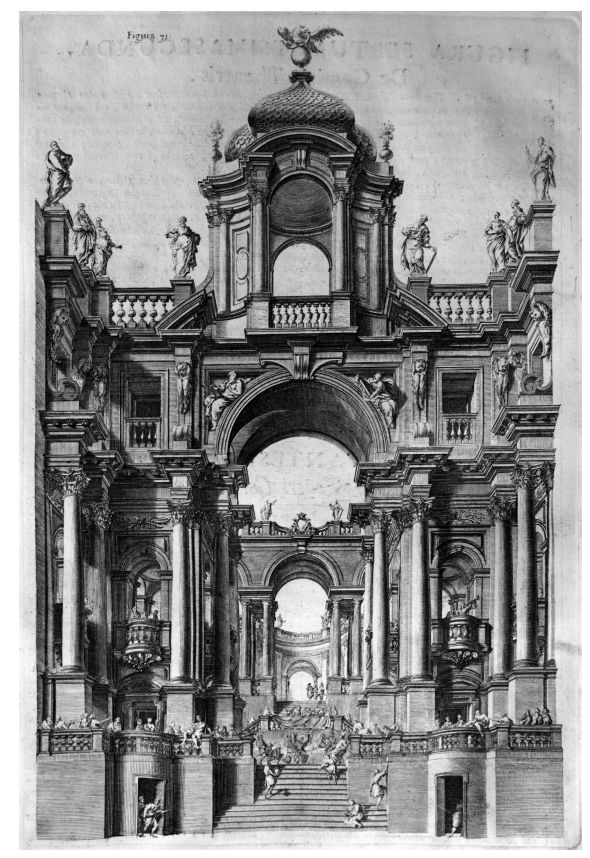

Figura 9. Lámina 71 del primer tomo de POZZO, ANDREA: Perspectiva pictorum et architectorum. Roma, por Giovanni Giacomo Komarek, 1693-1700. Biblioteca de la Real Academia de San Carlos de Valencia. Fotografía del autor.

El primero de ellos es el de la iglesia de Santa María de Oliva, trazada por Gil Torralba en 1705, aunque el proceso constructivo no sería emprendido de forma continuada hasta $1722^{22}$. Para el templo de Santa María la Mayor dieron trazas Juan Pérez, Rafael Martí y Gil Torralba, siendo elegida finalmente la de este último gracias al informe favorable que en 1705 emitieron desde Valencia Tomás Vicente Tosca y Juan Bautista Corachán ${ }^{23}$. En este informe los dos miembros del grupo de los novatores afirmaban haber seleccionado el proyecto de Torralba por su novedad y por la semejanza con las mejores iglesias de la ciudad de Roma.

El segundo caso es el de la enorme parroquial de San Juan Bautista de Alcalà de Xivert, proyectada por José Herrero en $1735^{24}$. En Alcalà de Xivert la intervención de Herrero se produce a raíz del envío a Valencia de los proyectos que habían presentado varios maestros de obras locales para ser examinados por una comisión de expertos. El recurso a la ciudad de Valencia se debió a la mediación del oratoriano Felipe Seguer, quien recurrió al dictamen de los maestros de obras José

22 COTS MORATO, FRANCISCO: Estudio histórico artístico del templo de Santa María la Mayor de Oliva. Oliva, Ayuntamiento, 1989.

${ }^{23}$ COTS MORATO, FRANCISCO: op. cit., pp. 26-29.

24 ALCAHALÍ, BARÓN DE: Alcalá de Chivert. Recuerdos históricos. Valencia, Tipografía Doménech, 1905. 
Vilar y Vicente Llorens y del escultor Andrés Robres. Inicialmente fue elegida la traza del maestro Juan Barceló pero, al parecer, José Herrero presentó un nuevo proyecto que finalmente fue el elegido. Para el éxito del proyecto de José Herrero resultó fundamental la disposición en planta escalonada de tres naves con las laterales cubiertas mediante cúpulas, punto sugerido por los maestros consultados por su relación con el medio arquitectónico romano y, en concreto, con la iglesia de San Carlo al Corso. La inclusión de naves laterales cubiertas mediante una sucesión de cúpulas respondió a un apunte del escultor de Valencia Andrés Robres, quien «tenía un libro todo de plantas de las mejores iglesias de Italia, y de una que hay en Roma sacó esta idea» ${ }^{25}$.

Ambos templos, Oliva y Alcalà de Xivert, tienen en común la referencia al medio romano y una estructura muy similar. En ambos casos el tradicional esquema jesuítico de cruz latina con capillas que definen un perímetro rectangular se enriquece notablemente al romper los muros de separación entre las capillas y cubrir estas con cúpulas notablemente iluminadas. El resultado es un riquísimo esquema de tres naves en el que las colaterales se configuran como una sucesión de unidades estructurales y lumínicas independientes con una potente secuencia rítmica.

Los referentes en el ambiente romano son muchos y su conocimiento por parte de los redactores y censores de ambos proyectos puede haberse producido a través de distintos medios, aunque algunos datos inducen a concretar un libro como fuente y modelo de la renovación de la tipología arquitectónica eclesiástica en la Valencia del siglo XVIII. Pese a la gran difusión de volúmenes ricamente ilustrados como II nuovo teatro delle fabriche, et edificii, in prospettiva di Roma moderna editado por Giovanni Giacomo Rossi en $1665^{26}$, o el publicado en varios volúmenes algunos años después por Domenico de Rossi27, el que recoge de forma más clara iglesias de tipología claustral con la nave flanqueada por series de cúpulas es el Insignium Romae Templorum ${ }^{28}$, una colección completa de plantas y alzados de las principales iglesias romanas publicada en 1684 que tuvo una amplia difusión en Europa $^{29}$ y presencia documentada en España a principios del siglo XVIII. ${ }^{30}$

25 Noticias sobre esta Iglesia Parroquial de Alcalá de Chivert con una emisión a lo último de las fiestas que se hicieron cuando se concluyó, documento transcrito en MESEGUER FOLCH, VICENTE ET ALII: La iglesia y el campanario de Alcalà de Xivert. Benicarló, Centre d'Estudis del Maestrat, 2003, p. 162.

26 ROSSI, GIOVANNI GIACOMO DE: I/ nuovo teatro delle fabriche, et edificii, in prospettiva di Roma moderna. Roma, 1665.

27 ROSSI, DOMENICO DE: Studio d'architettura civile. Roma, 1702, 1711 y 1721.

28 ROSSI, GIOVANNI GIACOMO DE: Insignium Romae Templorum. Prospectus exteriores interioresque. Roma, 1684. Véase el estudio introductorio de la edición a cargo de BARBEITO, JOSE MANUEL: Insignium Romae Templorum. Prospectus exteriores interioresque. Madrid, Instituto Juan de Herrera, 2004.

${ }^{29}$ Véase MARTÍNEZ MINDEGUÍA, FRANCISCO: «Insignium Romae Templorum Prospectus, la visión frontal de la arquitectura». Annali di architettura, 17, (2005), pp. 167-182.

30 En concreto en la biblioteca del arquitecto Pedro de Ribera. Véase VERDÚ, M.: El arquitecto Pedro de Ribera (1681-1742). Madrid, Instituto de Estudios Madrileños, 1998. 


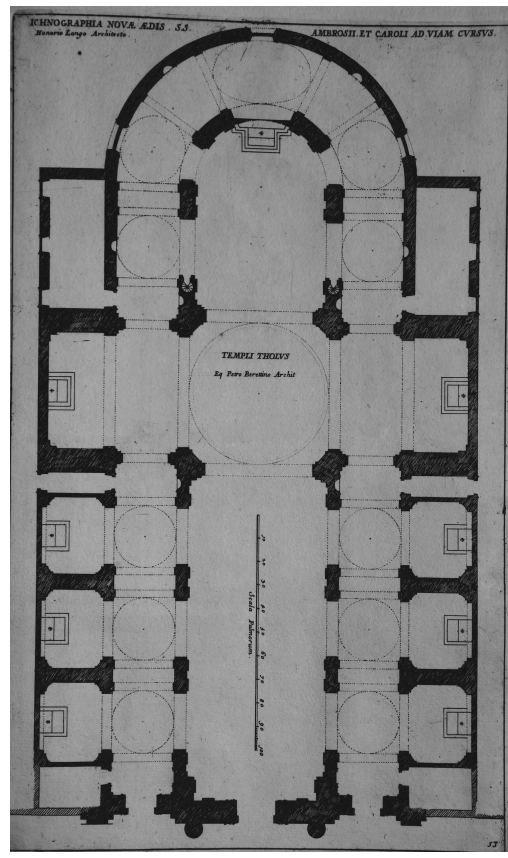

Figura 10. Lámina 53 del Insignium Romae Templorum de Giovanni Giacomo de Rossi en la que se representa la planta de la iglesia romana de los Santi Ambrogio e Carlo al Corso. 1684. Biblioteca de la Real Academia de San Carlos de Valencia. Fotografía del autor.

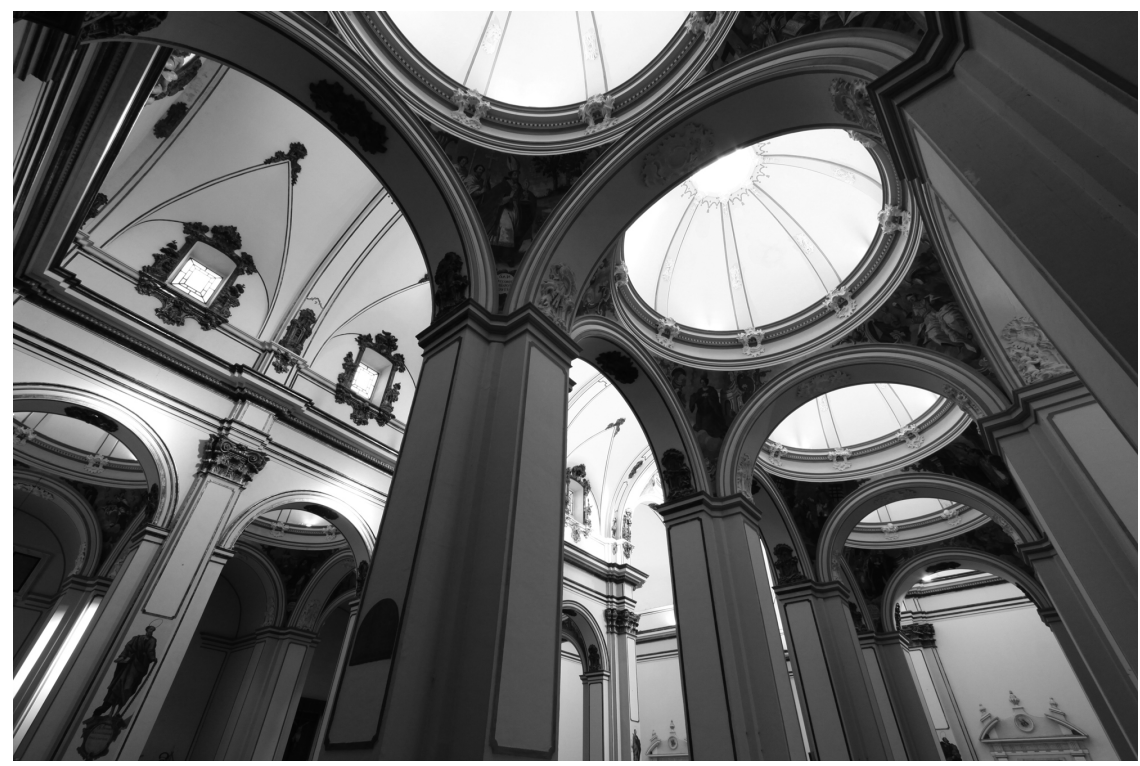

Figura 11. Templo parroquial de Alcalà de Xivert (Castellón). José Herrero. 1735. Fotografía del autor. 
El modelo claustral o criptocolateral en la cultura impresa italiana puede rastrearse desde el mismo Serlio, quien al reproducir el proyecto no realizado de Rafael para San Pedro del Vaticano ${ }^{31}$ recoge la articulación compleja de las colaterales mediante una sucesión de espacios intercomunicados y, en cierta medida, aislados de la nave principal debido al grosor de los pilares que los separan de ella $^{32}$. El mismo San Pedro construido, difundido ampliamente mediante graba$\operatorname{dos}^{33}$, y especialmente la obra de Maderno, pudo imponer, desde la autoridad de ser el centro de la cristiandad, la idea del modelo de planta claustral. El edificio, con naves laterales cubiertas mediante cúpulas, aparece así representado ya en $1613^{34}$, mostrando la articulación de la nave de Maderno mediante pilastras pareadas, la sucesión de cúpulas elípticas en el perímetro y la dilatación de los espacios cupulados mediante profundas capillas. También el tratado de Andrea Pozzo, ya en el primero de los volúmenes publicados, ofrece la imagen de un templo claustral, el de la iglesia de Sant'Ignazio ${ }^{35}$, con una amplia planta de cruz latina en la que tres tramos cuadrados con cúpula flanquean cada lado de la nave principal.

Sin embargo, el Insignium Romae Templorum ofrece todo un abanico de variaciones alrededor de la idea de la planta criptocolateral con mayor o menor grado de complejidad en la concepción de los espacios en torno a la nave. Desde San Pedro del Vaticano (lámina 9), del que no se representa el sistema de cubiertas, a la basílica de cinco naves de San Juan de Letrán (lámina 13). Más operativos desde el punto de vista de los maestros valencianos resultan los dibujos ofrecidos de templos como el Gesú (láminas 20, 21 y 22) y Sant'Andrea della Valle (lámina 46), con planta de cruz latina, alzado de pilastras pareadas el primero y pilastra con retropilastra el segundo, y capillas intercomunicadas por pequeños pasos sin que en las láminas se indique el tipo de cubierta empleado. Pero de entre estos edificios destacan dos iglesias con naves laterales constituidas por la sucesión de espacios cúbicos completamente abiertos y comunicados cubiertos mediante cúpulas que sí aparecen dibujadas. Son Sant'Ignazio (lámina 28), con tramos perfectamente cuadrados y Santi Ambrogio e Carlo al Corso (lámina 53), con tramos cuadrados intercomunicados y cubiertos con cúpula que se abren a capillas cerradas. Se trata, en este último caso, de una representación en planta que no se corresponde con la edificación de la iglesia romana en la que las naves laterales se cubren en realidad mediante bóvedas baídas y son las capillas, cerradas y separadas del espacio de las naves del templo, las que están rematadas con cúpulas. De hecho, la planta de Alcalà de Xivert, en la que el añadido de profundas capillas en el perímetro en-

31 SERLIO, SEBASTIANO: II primo libro d'Architettura di Sebastiano Serlio, bolognese. se ha empleado la edición de París, 1545, Lámina XXL.

32 Véase BRUSCHI, A, FROMMEL, C.L., WOLFF METTERNICH, F.G., THOENES, C.: San Pietro che non c'è. Da Bramante a Sangallo il Giovane. Milán, Electa, 1996.

33 THOENES, CHRISTOPHER: La fabbrica di San Pietro nelle incisioni dal Cinquecento all'Ottocento. Milán, II Polifilo, 2000.

${ }^{34}$ GREUTER, MATTHAEUS: Pianta della Basilica secondo Carlo Maderno. Roma, 1613. Véase THOENES, CHRISTOPHER, op. cit.

35 POZZO, ANDREA: op. cit., volumen I, Figura 93. 
Los libros de arquitectura en la Valencia del siglo XVIII: de los modelos del Barroco...

sancha las dimensiones de la planta, es una imitación casi exacta de la disposición romana del grabado de los Santi Ambrogio e Carlo al Corso.

El éxito de esta nueva tipología templaria, que se quiere a la romana, es indudable, y buena muestra de ello es, junto a los casos de Oliva y Alcalà, la multiplicación de templos con planta claustral. En Alboraia en $1701^{36}$, en Chiva en $1737^{37}$, o en L'Alcúdia en $1746^{38}$.

La arquitectura valenciana de la primera mitad del siglo XVIII se orientaba a través del libro impreso hacia la superación de un barroco autóctono y sobrecargado en lo decorativo buscando, como resulta patente en la documentación y en la realidad de las obras construidas, la apertura hacia concepciones más cultas del quehacer arquitectónico y mirando, fundamentalmente, a Italia. Prueba de este aperturismo es la publicación en la capital del reino de dos de los mejores tratados de arquitectura del Barroco español, el del Padre Tosca ${ }^{39}$ y el de Agustín Bruno Zaragozá ${ }^{40}$, que contribuyeron de manera decisiva a la vocación renovadora de la obra de algunos arquitectos y que pasaron de forma inmediata a formar parte de sus bibliotecas, tal y como muestra el inventario de los bienes del maestro de obras José Vilar de Claramunt en $1747^{41}$.

La importancia que se les dio en su momento a algunos de estos libros puede intuirse si se observa que, en 1750, cuando el maestro valenciano Cristóbal Herrero fallece en la lejana localidad zamorana de Molacillos, a la que había sido enviado por el arzobispo Mayoral para reformar su iglesia, lleva consigo el tratado de Tosca $^{42}$.

\section{ENTRE BARROCO Y ACADEMICISMO: LA BIBLIOTECA DE FELIPE $R U B I O$}

El auge de la cultura libresca y los cambios en el ejercicio de la arquitectura que de ella se derivarán pueden entreverse en la figura del maestro de obras y más tarde académico de San Fernando Felipe Rubio. Este notable arquitecto parecía destinado a regir los destinos de la incipiente Academia de San Carlos como protago-

${ }^{36}$ GONZÁLEZ TORNEL, PABLO: «El arquitecto barroco Francisco Padilla». Espacio, Tiempo y Forma, 17, (2004), pp. 121-148.

37 Archivo de Protocolos del Patriarca de Valencia (A.P.P.V.), notario Felipe Mateu, signatura 03467, 15 de agosto de 1737, fols. 162r-163v.

38 CHOVER MADRAMANY, J.: Reseña histórica de la edificación de la Iglesia Parroquial de San Andrés Apóstol de la Villa de Acudia de Carlet. Valencia, 1923, p. 29.

39 TOSCA, TOMÁS VICENTE: Compendio mathematico. Valencia, por Antonio Bordázar, 17071715.

40 BRIGUZ Y BRU, ATANASIO GENARO: Escuela de arquitectura civil, en que se contienen los ordenes de arquitectura, la distribucion de los planos de templos y casas, y el conocimiento de los materiales. Valencia, por Joseph de Orga, 1738.

41 A.P.P.V., notario Juan Antonio Espada, signatura 06766, 4 de marzo de 1747, s/f.

42 A.P.P.V., notario Joaquín Medina, signatura 03566, 26 agosto 1750, fols. 126v-129v. 
nista indiscutido de la junta preparatoria, pero su trayectoria se vería truncada al morir en 1767, un año antes de la oficialización de la segunda academia española ${ }^{43}$. Con una trayectoria poco conocida en la que destacan sus intervenciones en los templos de Santa Catalina de Valencia ${ }^{44}$ y la parroquia de Soneja ${ }^{45}$ es, sin embargo, la construcción de la Aduana de Valencia ${ }^{46}$ la que debió ser motivo de mayor orgullo para él, ya que en 1762 son los planos de este edificio los que el arquitecto envía a Madrid para ser aprobados por la Academia de San Fernando ${ }^{47}$.

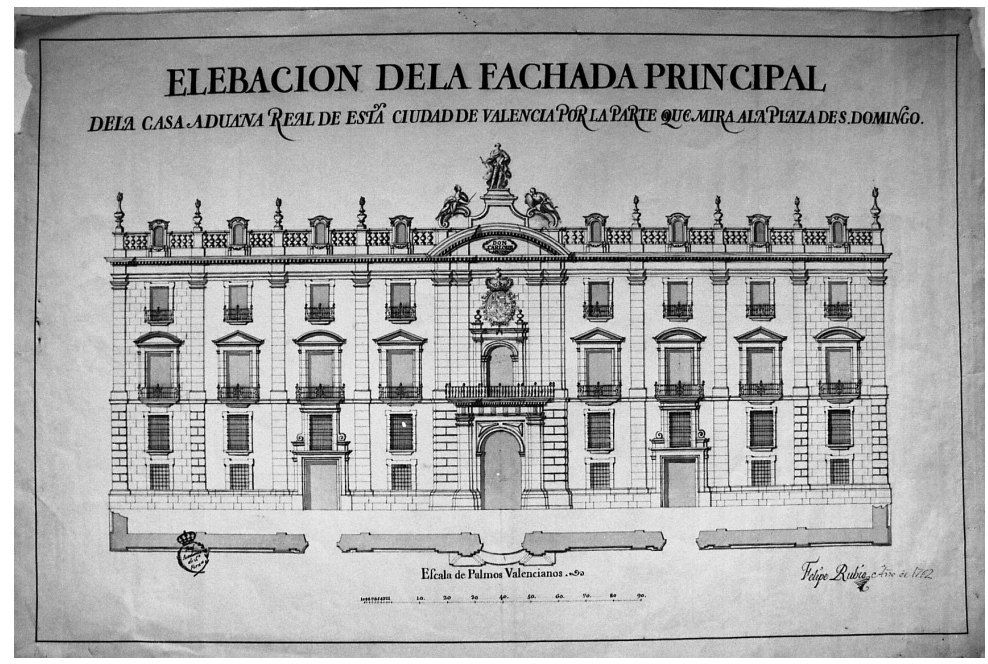

Figura 12. Frante del Palacio de la Aduana de Valencia presentado por Felipe Rubio a la Real Academia de Bellas Artes de San Fernando en 1762 para conseguir el grado de Académico de Mérito por

la Arquitectura. Dibujo A1023 del Archivo de la Real Academia de Bellas Artes de San Fernando.

La biblioteca de Felipe Rubio es conocida, en parte, a través del testamento del arquitecto ${ }^{48}$, en cuyo cuerpo se citan las obras clásicas de Palladio, Vitrubio y Serlio, y las modernas de Tomás Vicente Tosca, Agustín Bruno Zaragozá y la Aritmética de Juan Bautista Corachán ${ }^{49}$. También aparecen reseñados, sin identi-

${ }^{43}$ Para una reseña biográfica del arquitecto véase ARISTOY ALBERT, MARIO JOSÉ, Y CASAR PINZAZO, JOSÉ IGNACIO: «Felipe Rubio, apuntes para una biografía». En VV. AA.: El Palacio de Justicia de Valencia: de Casa Aduana Real a sede del Tribunal Superior de Justicia. Valencia, Generalitat Valenciana, 1999, pp. 68-82.

44 PINGARRÓN, FERNANDO: «Algunos documentos sobre las reformas tardobarrocas de las iglesias de San Andrés, Santa Catalina y San Martín en Valencia a mediados del siglo XVIII». Saitabi, 47, (1997), pp. 327-363.

45 IQUINO PARRA, FÉLIX: Historia de Soneja. Valencia, 1982, pp. 113-123.

46 VV. AA.: El Palacio de Justicia de Valencia: de Casa Aduana Real a sede del Tribunal Superior de Justicia. Valencia, Generalitat Valenciana, 1999.

47 Planos A1022, A1023 y A1024 del Archivo de la Real Academia de Bellas Artes de San Fernando.

48 PINGARRÓN, FERNANDO: «El arquitecto setecentista valenciano Felipe Rubio y Mulet y su familia». Archivo de Arte Valenciano, 68, (1987), pp. 67-76.

49 CORACHÁN, JUAN BAUTISTA: Arithmetica demonstrada theorico-practica, para lo mathematico, y mercantil: explicanse las monedas, pesos, y medidas de los hebreos, griegos, romanos.... Valencia, por Jayme Bordázar, 1699. 
Los libros de arquitectura en la Valencia del siglo XVIII: de los modelos del Barroco...

ficar, dos tomos más de arquitectura, un tercero de la misma temática en francés, y uno de Medrano que, probablemente, se trate de la obra de arquitectura militar El arquitecto perfecto en el arte militar ${ }^{50}$.

Además, en la actualidad conocemos algunos componentes más de la cultura libresca de Felipe Rubio gracias al inventario de los bienes que, a la muerte de su hermana María, son identificados como pertenecientes a la herencia del padre de ambos, Felipe Rubio el Mayor ${ }^{51}$. Entre estos aparecen los ya sobradamente conocidos Pozzo, Tosca, Serlio, del que se constatan dos ejemplares, uno en castellano y otro en italiano y latín, Alberti o Vignola. La obra de Caramuel, con su carácter especulativo sobre el lenguaje clásico y su aplicación de la geometría a la arquitectura, se ve reforzada por la presencia en el inventario de la Escuela de Palas de su discípulo Lorenzo Chafreón ${ }^{52}$. A estos se añaden algunos libros de complicada identificación como un volumen de «anivelaciones y alturas», la Astrolabia de Juan Estoferino o un impreciso «Señeri» que probablemente se trate de alguna de las obras devocionales de Paolo Segneri. Sin embargo, los dos ejemplares de mayor relevancia para el medio arquitectónico valenciano son los reseñados como «David» y «Escuela de San Phelipe Neri». Este segundo se trata, sin duda, de la obra de Juvarra acerca de la sede del Oratorio en Turín ${ }^{53}$, y en cuanto al ambiguo David, a pesar de la posibilidad de que se trate de una obra de temática bíblica, resulta sugestiva la posibilidad de que refiera al libro sobre las ruinas de Grecia publicado por Julien-David Le Roy en $1758^{54}$, lo que implicaría una temprana vocación arqueológica por parte de la arquitectura valenciana de mediados del siglo XVIII.

Los libros citados, a los que cabría añadir alguno más detectado en informes arquitectónicos emitidos por estos años ${ }^{55}$, establecen un panorama muy heterogéneo con respecto a la formación de los arquitectos de más importancia y su-

50 FERNÁNDEZ DE MEDRANO, SEBASTIÁN: El arquitecto perfecto en el arte militar. Bruselas, Lamberto Marchand, 1700. Véanse LEÓN TELLO, F.J.: «Sebastián Fernández Medrano, ingeniero y teórico de la arquitectura militar». En V Jornadas de Arte. Velázquez y el arte de su tiempo. Madrid, CSIC, 1991, pp. 225-231, y GUTIÉRREZ, R., Y ESTERAS, C.: Territorio y fortificación. Vauban, Fernández de Medrano, Ignacio Sala y Félix Prosperi. Influencia en España y América. Madrid, Tuero, 1991, pp. 49-60.

51 A.R.V., Protocolos Notariales, notario Agustín Bonet, signatura 5010, 8 de enero de 1766, fols. $229 \mathrm{v}-243 \mathrm{r}$.

52 CHAFREÓN, LORENZO: Escuela de Palas o sea curso mathematico. Tomo I que contiene la Arithmetica, Geometria Especulativa, Practica, Logares planos, Dados de Euclides, Esphera, Geographia, Algebra Numerosa, y Especiosa, Trigonometria, y Logarithmica. Tomo Il que contiene el arte militar. Milán, en la Emprenta Real, por Marcos Antonio Pandulpho Malatesta, 1693.

53 JUVARRA, FILIPPO: Modello della Chiesa di S. Filippo per li PP. Dell'Oratorio di Torino. Turín, nella Stamperia Reale, 1758.

${ }_{54}$ LE ROY, JULIEN-DAVID: Les ruines des plus beaux monuments de la Grece. Ouvrage divisé en deux parties, où l'on considere, dans la premiere, ces Monuments du côté de l'Histoire; et dans la seconde, du côté de l'Architecture. París, Chez H. L. Guerin \& L. F. Delatour, 1758. Se ha consultado la traducción inglesa LE ROY, JULIEN-DAVID: The Ruins of the Most Beautiful Monuments of Greece. Los Ángeles, Getty Publications, 2004 (con introducción de Robin Middleton).

55 GIL SAURA, YOLANDA: Arquitectura barroca en Castellón. Castellón, Diputació de Castelló, 2004, constata, por ejemplo, la presencia en 1749 de la obra de Rubens Palazzi di Genova, la Aritmética Universal de José Zaragozá, el libro de matemáticas de Jacques Besson o el tratado de arquitectura militar de Cristóbal de Roxas (p. 192), y en 1754 la obra de Domenico Fontana Della Transportatione dell'obelisco vaticano (p. 203). 
gieren actitudes ambivalentes ante el hecho arquitectónico. Por una parte es interesante constatar que el arquitecto de mayor prestigio en la ciudad de Valencia en los años centrales del siglo conocía no sólo las cartillas tradicionales de Serlio o Vignola, sino que en su formación tenían una importante presencia las obras relativas a las matemáticas y geometría, no sólo por la obra de Corachán sino por los ejemplares de arquitectura militar, que contenían importantes enseñanzas en este campo. Un segundo grupo de obras parecen derivar los aspectos formativos del arquitecto hacia visiones heterodoxas del empleo del lenguaje clásico en sentidos bien distintos. Por un lado la presencia de Caramuel, cuyo peso sobre la arquitectura barroca valenciana ha quedado sobradamente explicitado, y por otro la de Pozzo, cuya obra sabemos presente en la ciudad inmediatamente después de su publicación. Ambas obras podrían ser consideradas anticlásicas desde una perspectiva académica y el impacto sobre la arquitectura de la segunda mitad del siglo XVIII en Valencia es ciertamente limitada. Las interpretaciones y aplicaciones más atrevidas de los principios de Caramuel habían sido realizadas décadas atrás, y el lenguaje escenográfico de Pozzo, aunque pervivió en el diseño de retablos, presenta escasas aplicaciones a la construcción.

De entre los libros reseñados los que suponen una mayor novedad en el medio valenciano son el de Juvarra y el posible Le Roy. El primero de ellos, cuya importancia en la obra de Ventura Rodríguez fue señalada por Chueca con respecto a la planta del templo de San Marcos de Madrid ${ }^{56}$, es una magnífica colección de veinte láminas que describe cada uno de los detalles de la sede de los oratorianos en la capital de los Saboya. El templo, con una planta basada en el esquema jesuítico inscrito en un rectángulo, presenta gran cantidad de sugestiones en los particulares. El conjunto emplea un lenguaje tardobarroco con una importante impronta clasicista y detalles decorativos de muy alto nivel, pero lo que sorprende en la concepción de la iglesia, tanto interior como exteriomente, es la fuerza tectónica de los órdenes. Todo el edificio, tanto en sus fachadas como en su alzado interior, se concibe como un sólido entramado estructural basado en la repetición de colosales soportes de orden gigante que marcan las líneas de fuerza. De esta manera se reconoce a la perfección el carácter sustentante de los soportes y al espectador le resulta sencillo desentrañar el funcionamiento de la estructura. La sobreabundancia decorativa, la multiplicación de altares, o la ulterior subdivisión del alzado en varias alturas dentro de los intercolumnios, no obstaculizan en ningún momento la percepción clara de ese entramado estructural que, marcado por los soportes gigantes, devuelve el valor tectónico a los órdenes del lenguaje clásico en una suerte de inspiración neoborrominesca que bebe de las ordenaciones de la capilla de los Reyes Magos o de San Juan de Letrán y, en última instancia, de los Palacios Capitolinos de Miguel Ángel. En el medio valenciano, además de otros reflejos de mayor calado, pueden rastrearse huellas del conocimiento de los magníficos

56 CHUECA, FERNANDO: «Ventura Rodríguez y la escuela barroca romana». Archivo Español de Arte, 52, (1942), pp. 185-210. 
Los libros de arquitectura en la Valencia del siglo XVIII: de los modelos del Barroco...

grabados del proyecto de Juvarra similares a las concomitancias detectadas por Chueca con el templo madrileño de San Marcos. Así, en la planta de la capilla de San Vicente Ferrer del convento de dominicos de la capital, de dilatada y azarosa construcción en la que tuvo mucho que ver el cuñado de Felipe Rubio, Antonio Gilabert ${ }^{57}$, se emplea el mismo esquema planimétrico de la capilla dibujada por Juvarra en la que el eje longitudinal se compone de tres células espaciales interpenetradas. Esta disposición, que sería aprovechada en todas sus posibilidades espaciales por Ventura Rodríguez, se disuelve sin embargo en la obra valenciana conforme se asciende en alzado y se adoptan soluciones mucho más tradicionales.

La obra de Julien-David Le Roy, ricamente ilustrada mediante el grabado, tiene un carácter similar a otros muchos libros aparecidos durante el siglo XVIII, a medio camino entre el libro de viajes, la visión romántica y el tratado de arquitectura. Se ilustra también de acuerdo a esta concepción híbrida, y así, junto a las hermosísimas estampas que tratan de ser instantáneas de las ruinas más evocadoras o reconstrucciones ideales de los monumentos, aparecen láminas verdaderamente normativas en las que plantas, alzados, órdenes y detalles arquitectónicos aparecen descritos con la minuciosidad de un profesional de la construcción interesado en proporcionar modelos veraces y fidedignos de la arquitectura antigua.

Fruto de cultura arquitectónica de Felipe Rubio es su práctica constructiva que, como ocurre con respecto a los libros que compusieron su biblioteca y la de su padre, se caracteriza por la falta de un carácter normativo y le permite hacer frente a obras animadas por espíritus muy diversos. Esta es la sensación que se tiene al acercarse a obras tan dispares como la desaparecida reforma de Santa Catalina, la parroquial de Soneja o el Palacio de la Aduana. La primera de ellas estaba caracterizada por un exuberante Barroco decorativo basado en la aplicación de adherencias de estuco, y en Soneja, la planta claustral tradicional se anima en lo ornamental mediante delicadas rocallas. Sin embargo, en la más tardía de sus obras, el Palacio de la Aduana, parece recuperarse el sentido normativo del orden $y$, rompiendo con la tradición valenciana que rara vez ordenaba las fachadas de las obras civiles, organiza las cuatro caras del cubo edificado mediante atirantadas pilastras gigantes sobre pedestal que recorren toda la altura, como en las ilustraciones de Juvarra, y reduce drásticamente el ornamento, tal vez influido por Le Roy. El Palacio de la Aduana es una obra en la que no se renuncia a las licencias oblicuas en la portada o a un cierto tono áulico tardobarroco no exento de modernas citas cultas como las mansardas del tejado. Estas últimas parecen tomadas directamente en su concepción de la estampa 47 de la Escuela de Arquitectura Civil de Agustín Bruno Zaragozá, y en la morfología de sus elementos compositivos de las estampas 37 y 38 del mismo libro. Pero, en conjunto, en el Palacio de la Aduana parece atemperarse un nuevo clasicismo de mayor empaque cosmopolita con respecto a la arquitectura construida en el reino durante las décadas anteriores, basado, ante la ausencia de viajes conocidos por parte de Felipe Rubio, de

57 Véase BÉRCHEZ, JOAQUíN: Los comienzos de la arquitectura..., pp. 217-241. 
manera exclusiva en el estudio de los textos y estampas que una incipiente y fragmentaria cultura arquitectónica libresca proporcionaba a algunos arquitectos en los años centrales del siglo XVIII.

\section{LA ACADEMIA DE SAN CARLOS Y LOS MODELOS}

En directo solapamiento con el quehacer arquitectónico de Felipe Rubio se haya el proceso de creación de la Real Academia de Bellas Artes de San Carlos, de cuya biblioteca se conservan dos inventarios, fechados en 1766 y 1767, que pueden resultar iluminadores acerca de los presupuestos teóricos que animaron la actividad de los primeros arquitectos académicos ${ }^{58}$. Conviene recordar que en los momentos germinales de la creación de la Academia de San Carlos figuran como principales protagonistas los arquitectos Felipe Rubio y Vicente Gascó, quedando este último al frente de la sección de arquitectura a la muerte de Rubio en 1767.

En 1767 ya figuraban en los anaqueles de San Carlos la descripción del Palacio de Caserta ${ }^{59}$, regalo del Intendente, el libro festivo de la llegada de Carlos III a Barcelona ${ }^{60}$, regalo de Joseph Moles, la Perspectiva de Andrea Pozzo, propiedad de la Academia, el Vitrubio de Galiani ${ }^{61}$, regalo de San Fernando, la descripción del Oratorio de Turín de Filippo Juvarra, comprado, el libro de arquitectura de Paul Decker ${ }^{62}$, de la Academia, el libro sobre las ruinas de Palmira de Wood ${ }^{63}$, comprado, ediciones no precisadas de Vignola y Serlio, compradas, una edición tardobarroca de Palladio ${ }^{64}$, regalo de San Fernando, el tratado de arquitectura de Antonio Labacco, la Perspectiva de Barbaro ${ }^{65}$, comprada, la Perspectiva de Vignola comentada por Danti6 ${ }^{6}$, comprada, el Museo Pictórico de Palomino ${ }^{67}$, el libro de Za-

58 BÉRCHEZ, JOAQUÍN: Arquitectura y academicismo. Valencia, Alfonso el Magnánimo, 1987, pp. 295-303.

59 VANVITELLI, LUIGI: Dichiarazione dei Disegni del Reale Palazzo di Caserta alle Sacre Reali Maestà di Carlo Re delle Due Sicilie e di Gerus., Infante di Spagna, Duca di Parma e di Piacenza, Gran Principe ereditario diToscana, e di Maria Amalia di Sassonia Regina. Nápoles, Nella Regia Stamperia, 1756.

60 Mascara Real executada por los Colegios y Gremios de la ciudad de Barcelona para festejar el feliz deseado arribo de nuestros Augustos Carlos III y D. Maria Amalia de Saxonia. Barcelona, Thomas Piferrer, 1764.

61 VITRUVIO POLLIONE, MARCO: Architettura. Nápoles, Nella Stamperia Simoniana, 1758.

62 DECKER, PAUL: Fürstlincher Baumeister oder Architecturae civilis. Augsburgo, 1716. 1753.

63 WOOD, ROBERT: Les ruynes de Palmyre, autrement dite Tedmor, au desser. Londres, A. Millar,

64 PALLADIO, ANDREA: Architettura di Andrea Palladio vicentino.... Venecia, apresso Angiolo Pasinelli, 1740-1748.

65 BARBARO, DANIELE: Pratica della Perspettiva / di Monsignor Daniel Barbaro eletto Patriarca D'Aquileia; opera molto utile a Pittori, a Scultori, \& Architetti; Con due tauole, una de capitoli principali, l'altra delle cose notabili contenute nella presente opera. Venecia, Appresso Camillo et Rutilio Borgominieri fratelli, al segno di S. Giorgio, 1569.

66 VIGNOLA, IACOMO BAROZZIO DA: Due Regole della Prospettiva Pratica. Roma, ad instanza di Filippo de Rossi, Nella Stamperia del Mascardi, 1644

67 PALOMINO DE CASTRO Y VELASCO, ANTONIO: Museo Pictórico y Escala Optica. Madrid, por Lucas Antonio de Bedmar, 1715. 
Los libros de arquitectura en la Valencia del siglo XVIII: de los modelos del Barroco...

baglia que incluía el tratado quinientiesta de Domenico Fontana ${ }^{68}$, regalo del arcediano de Alcira, y varias estampas de Piranesi regaladas por Pascual Moles junto a otras láminas y libros de difícil identificación. Sobre el inventario de 1767, y con letra diferente al resto de anotaciones, las únicas nuevas entradas registradas son el libro sobre las antigüedades de Herculano ${ }^{69}$, y la obra de Cayo Salustio ${ }^{70}$, ambas regaladas y posteriores a la fecha del documento.

La mayoría de los libros de arquitectura con que contó la incipiente Academia de San Carlos en su modesta biblioteca responde a adquisiciones, algunos fueron regalos y sólo dos, los tratados de Pozzo y Decker, aparecen como propios, siendo, probablemente, resultado de la herencia recibida del anterior intento académico de Santa Bárbara ${ }^{71}$. El conjunto resulta tremendamente heterogéneo y difícil adivinar una línea rectora en el mecanismo de la creación de un ideario teórico para los arquitectos de la institución. Los tratados tradicionales sobre el lenguaje clásico se entremezclan con hermosas ediciones quinientistas de libros poco frecuentes, tratados decididamente barrocos y alguna incipiente señal de interés por la recuperación arqueológica de la arquitectura antigua que se estaba llevando a cabo en ámbitos geográficos lejanos al valenciano. El espíritu de la colección parece acercarse en gran medida al de la biblioteca estrictamente contemporánea de la saga de arquitectos Rubio, aunque en el caso de la Academia la orientación de las adquisiciones, aún siendo muy variada, parece soslayar los aspectos técnicos de la construcción en beneficio de una cultura puramente visual en la que se priman los libros ilustrados con hermosas composiciones arquitectónicas.

Por todo lo expuesto será probablemente más útil aproximarse a la efectiva aplicación de unos u otros modelos por parte de los arquitectos académicos y, en concreto, a las elecciones que el director de la sección de arquitectura durante la primera andadura de la Academia, Vicente Gascó, formuló en sus proyectos. La aceptación, o menos, de unas u otras formulaciones teóricas en torno a la arquitectura reviste especial importancia para la comprensión de la orientación tomada por la incipiente Academia de San Carlos, pues su coyuntura fue del todo diferente a la de San Fernando.

Como ha estudiado Alicia Quintana ${ }^{72}$, los cargos de la sección de arquitectura de la academia madrileña, inaugurada en 1752 y en funcionamiento como junta preparatoria desde 1744, fueron copados, durante los primeros años, por los ar-

68 ZABAGLIA, NICOLA: Castelli e ponti di Maestro Niccola Zabaglia : cum alcune ingegnose pratiche e con la Descrizione del trasporto dell Obelisco Vaticano e di altri del cavalieri Domenico Fontana. Roma, nella Stamperia di Niccolo e Marco Pagliarini, 1743.

69 BAYARDI, OTTAVIO ANTONIO: De' Bronzi di Ercolano e contorni : incisi con qualche spiegazione. Nápoles, nella Regia Stamperia, 1754-1779.

70 SALUSTIO CRISPO, CAYO: Conjuración de Catilina y la Guerra de Yugurta. Madrid, por Joaquin Ibarra, Impresor de Camara del Rei Nuestro Señor, 1772.

71 Véase sobre este primer conato académico BÉRCHEZ, JOAQUÍN: Arquitectura y academicismo. pp. 19-107.

72 QUINTANA MARTÍNEZ, ALICIA: La arquitectura y los arquitectos en la Real Academia de Bellas Artes de San Fernando. Madrid, Xarait, 1983. 
tistas italianos de la corte de Felipe V y Fernando VI. Sólo con el avance del proceso académico Ventura Rodríguez y Diego Villanueva tomarían protagonismo, siendo Rodríguez el primer arquitecto en ocupar el cargo de Director General de la Academia. La impronta arquitectónica cortesana y tardobarroca de las primeras décadas de existencia de la institución resultaba, pues, inevitable, y sólo de manera paulatina fue tomando fuerza la idea de una recuperación de tipo arqueológico del lenguaje clásico que es perfectamente apreciable en las convocatorias de los premios generales de arquitectura, en los que el dibujo de los principales monumentos del barroco madrileño irá siendo substituido por el de rigurosos temas antiquizantes ${ }^{73}$. En el proceso de cambio del ideario estético de San Fernando resulta fundamental, junto a los libros y estampas presentes en su biblioteca ${ }^{74}$, la existencia de pensiones de estudios en Roma que permitieron a los arquitectos formados en la institución entrar en contacto con realidades culturales distintas a las de la corte ${ }^{75}$. Los años en Roma de Miguel Fernández, José de Hermosilla, Domingo Lois Monteagudo o Juan de Villanueva, durante los que se les exigía el puntual envío de dibujos de las principales ruinas de la ciudad, supusieron una visión directa del antiguo de la que careció la Academia de San Carlos, y los distintos puntos de partida de ambas instituciones, así como la diversidad de medios de que dispusieron, resultarían fundamentales en la plasmación y evolución de idearios diferentes.

Una primera aproximación al ideario de los arquitectos preacadémicos valencianos pueden proporcionarla las colecciones de dibujos presentados en 1762 por Felipe Rubio y Vicente Gascó a la Real Academia de San Fernando de Madrid para la obtención del grado de académicos de mérito. Se trataba de un paso previo a la consolidación del proyecto de academia con patrocinio real que, con el nombre de San Carlos, vería publicados sus estatutos en 1768, y este mismo sentido tenía el envío a Madrid en 1761 de varias obras por parte de escultores y pintores de la ciudad ${ }^{76}$. Rubio mandó a la corte los planos del Palacio de la Aduana que acababa de concluir ${ }^{77}$, mientras que Vicente Gascó envió el proyecto de una basílica columnaria de tres naves ${ }^{78}$.

Los referentes culturales del proyecto de la Aduana, ya comentados, la integran dentro del clasicismo autóctono con los tintes cosmopolitas que el arquitecto pudo extraer de la biblioteca familiar. Por el contrario, la propuesta de Gascó re-

73 Véase RODRÍGUEZ RUIZ, DELFÍN: Hacia una nueva idea de la arquitectura. Premios generales de arquitectura de la Real Academia de Bellas Artes de San Fernando (1753-1831). Madrid, Comunidad de Madrid, 1992.

74 BEDAT, CLAUDE: «La Biblioteca de la Real Academia de San Fernando en 1793». Academia, 25, (1967), pp. 5-52, y 26, (1968), pp. 31-86.

75 Véase al respecto MONLEÓN, PEDRO: Arquitectos españoles en la Roma del Grand Tour 17461796. Madrid, Abada Editores, 2003.

76 IGUAL ÚBEDA, ANTONIO: «Las Reales Academias de Bellas Artes de San Fernando y San Carlos, y el gremio de albañiles de Valencia». Archivo de Arte Valenciano, 28, (1957), pp. 57-76.

77 Planos A1022, A1023 y A1024 del Archivo de la Real Academia de Bellas Artes de San Fernando.

78 Planos A4441, A4442, A4443 y A4444 del Archivo de la Real Academia de Bellas Artes de San Fernando. 
Los libros de arquitectura en la Valencia del siglo XVIII: de los modelos del Barroco...

sulta completamente ajena a la realidad arquitectónica valenciana y aún hispana. El arquitecto proponía, en fechas tan tempranas como 1762, una basílica columnaria a la antigua en la que el espacio de la nave central estaba delimitado por una fría sucesión de columnas sobre las que corría un arquitrabe continuo. Una estructura casi griega que se continuaba en el ábside semicircular y a la que se entraba a través del bosque columnario del frontis de templo clásico propuesto como fachada.

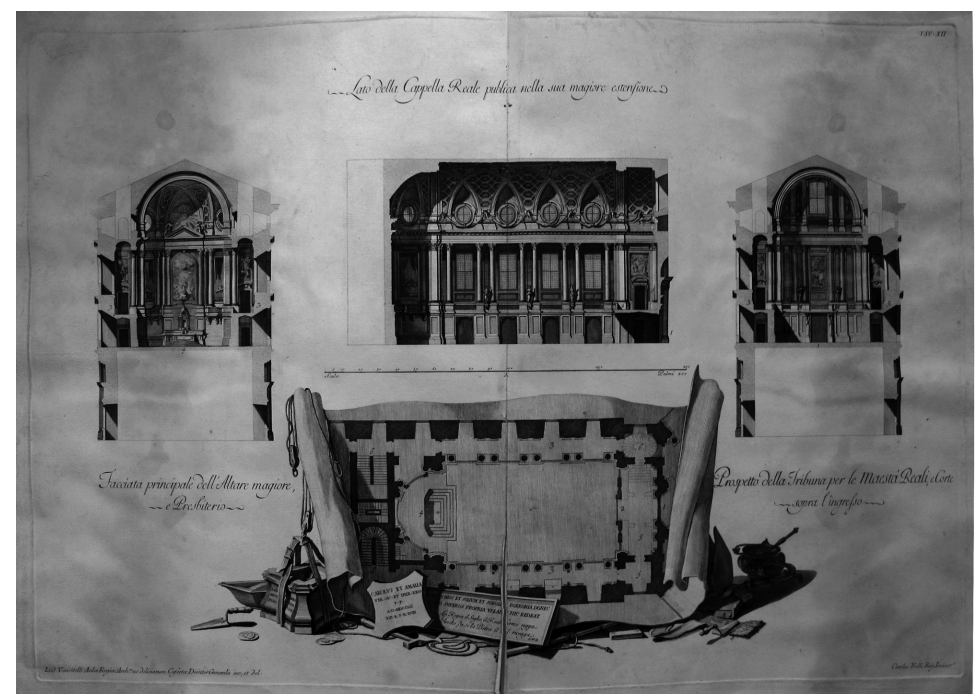

Figura 13. Lámina XII de VANVITELLI, LUIGI: Dichiarazione dei Disegni del Reale Palazzo di Caserta alle Sacre Reali Maestà di Carlo Re delle Due Sicilie e di Gerus., Infante di Spagna, Duca di Parma e di Piacenza, Gran Principe ereditario diToscana, e di Maria Amalia di Sassonia Regina. Nápoles, Nella Regia Stamperia, 1756. Biblioteca de la Real Academia de San Carlos de Valencia. Fotografía del autor.

Ambos proyectos obtuvieron el nombramiento como académico de mérito para sus autores, prueba de la ambigua actitud de la Academia de San Fernando durante estos años. Sin embargo, la modernidad de la propuesta de Gascó resulta indiscutible y, como ha sido indicado ${ }^{79}$, su concepción neoantigua extremadamente avanzada para el momento. De hecho, una propuesta de este calado rupturista, que renunciaba tanto a la tradición constructiva valenciana como a las contemporáneas tendencias italianizadas y afrancesadas de la corte, no se producirá en el medio madrileño hasta la construcción, a partir de 1782, veinte años después de la propuesta de Gascó, del Oratorio del Caballero de Gracia según proyecto de Juan de Villanueva ${ }^{80}$.

79 BÉRCHEZ, JOAQUÍN: Arquitectura y academicismo. pp. 116-118.

80 MONLEÓN GAVILANES, PEDRO: Juan de Villanueva. Madrid, Akal, 1998, pp. 121-124. 
Las fuentes empleadas por Gascó en el planteamiento general de la basílica columnaria arquitrabada pueden rastrearse con facilidad en la cultura libresca de su entorno inmediato. Así, en la lámina XII del libro de Vanvitelli sobre el palacio de Caserta, se plasma la planta y alzados de la capilla de la residencia real, con una estructura similar a la del proyecto del arquitecto valenciano. Nada tienen que ver, por el contrario, el refinado afrancesamiento de las columnas binadas de VanviteIli o sus detalles decorativos tardobarrocos con el proyecto de Gascó, con un lenguaje totalemente depurado cuyo sabor antiquizante se acentúa en el frente templario hexástilo.

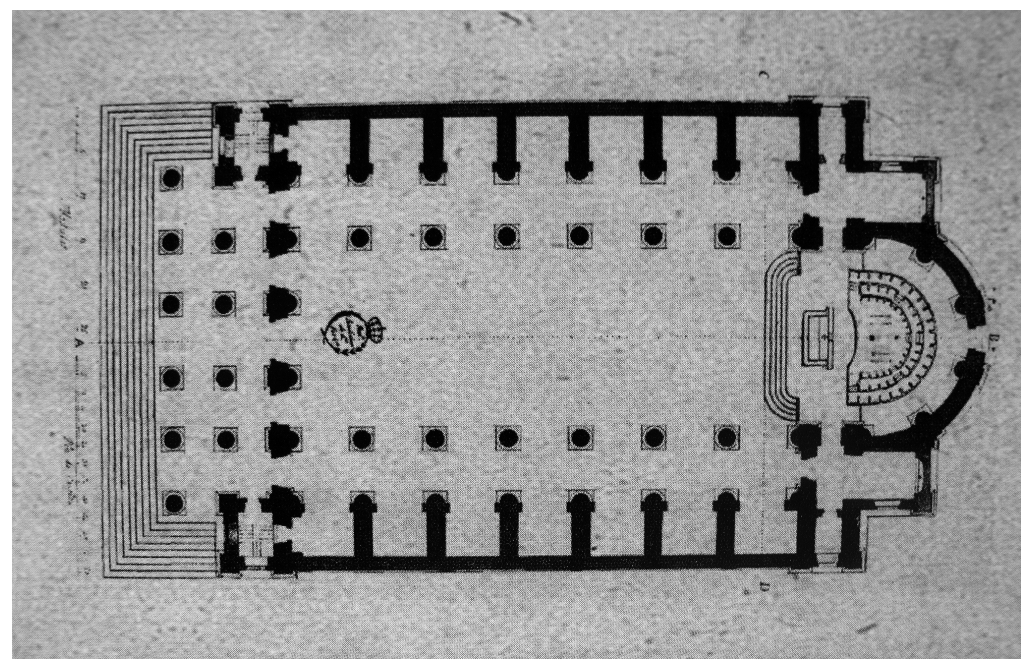

Figura 14. Planta de Iglesia presentada por Vicente Gascó a la Real Academia de Bellas Artes de San Fernando en 1762 para conseguir el grado de Académico de Mérito por la Arquitectura. Dibujo A4441 del Archivo de la Real Academia de Bellas Artes de San Fernando.

La temprana muerte de Felipe Rubio en 1767 y el ascenso de Vicente Gascó al puesto de director de arquitectura harían que los planteamientos más avanzados de éste tuvieran un amplio protagonismo en la actividad de la recién creada Academia de San Carlos $^{81}$. Una de las obras en las que puede constatarse la vigencia de esta recuperación arqueológica del antiguo es en la Capilla del Carmen del convento homónimo en Valencia, estructura oval cubierta con cúpula acasetonada que, proyectada por Gascó, se erige en muestra madura del incipiente academicismo valenciano ${ }^{82}$.

81 Sobre Vicente Gascó véase JANINI DE LA CUESTA, ÁLVARO: Las trazas y la obra del arquitecto Vicente Gascó. Valencia, tesis doctoral inédita leída en la Universitat de València, 1993.

82 Véanse sobre la capilla y el convento los trabajos de GARCÍA HINAREJOS, DOLORES: La arquitectura del Convento del Carmen de Valencia. Valencia, Colegio Oficial de Arquitectos de la Comunidad Valenciana, 1988, e Historia y arquitectura del Convento del Carmen de Valencia. Valencia, Generalitat Valenciana, 2009. 


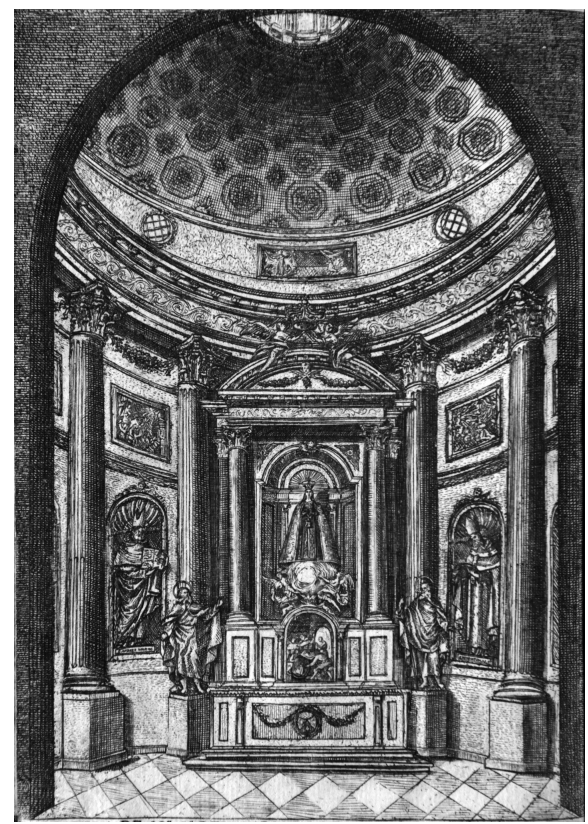

Figura 15. MARTÍN MALO, LUÍS: La capilla de nuestra señora del Carmen. Valencia, en la imprenta de Joseph y Thomas de Orga, 1784. Original de la Biblioteca de la Universitat de València. Fotografía del autor.

Dentro del proceso de la edificación de la capilla, en 1776, con motivo de la finalización de las obras estructurales, Gascó emite un informe en el que da las pautas para la ordenación y decoración del interior ${ }^{83}$. La definición de Gascó de cada uno de los ornatos que deben adjetivar el cilindro oval cupulado de la Capilla del Carmen es concisa y tiene un carácter muy concreto. Así, se emplean con profusión términos como gota, filete, bordón, hoja de laurel o meandro griego, léxico netamente antiquizante que muestra el carácter libresco de buena parte de la cultura arquitectónica del relator. Pero si la terminología hace intuir la aplicación por parte del arquitecto de un clasicismo de libro, la confirmación llega de la mano de los modelos que, directamente, se citan en varios puntos de la explicación. A parte de las referencias vagas a la antigüedad, se citan Palladio y las Ruinas de Palmira. Ambos libros aparecen en el inventario de la Academia de Bellas Artes de San Carlos en $1767^{84}$. Son la Architettura di Andrea Palladio vicentino de 1740 en italiano y francés y Les ruynes de Palmyre de 1753, el primero regalado por la Real Academia de San Fernando a su hija valenciana y el segundo comprado por la de San Carlos.

${ }_{83}$ A.R.V., Protocolos Notariales, notario Feliciano Blasco, signatutra 304, 9 de diciembre de 1776, fols. $107 v-112 r$.

84 BÉRCHEZ, JOAQUÍN: Arquitectura y academicismo. pp. 298-303. 


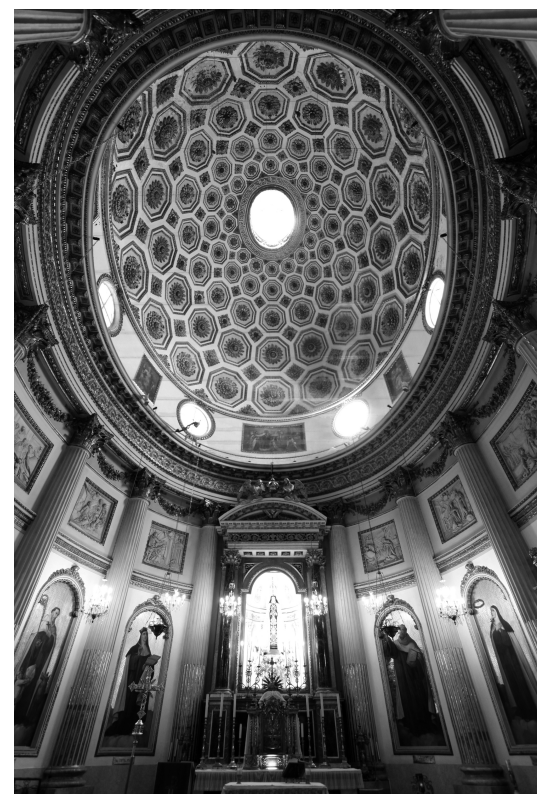

Figura 16. Vicente Gascó. Capilla del Carmen en el convento homónimo, Valencia. Revestimiento decorativo iniciado en 1776. Fotografía del autor.

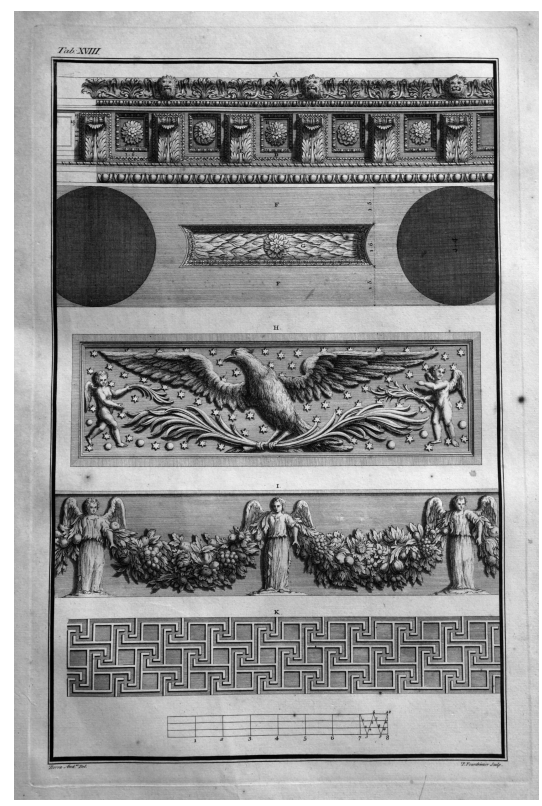

Figura 17. Lámina XVIII de WOOD, ROBERT: Les ruynes de Palmyre, autrement dite Tedmor, au desser. Londres, A. Millar, 1753. Biblioteca de la Real Academia de San Carlos de Valencia. Fotografía del autor. 
Los libros de arquitectura en la Valencia del siglo XVIII: de los modelos del Barroco...

Se trata, en ambos casos, de libros cuidadamente ilustrados por medio del grabado, aunque de signo netamente distinto. El Palladio de 1740 recoge los libros del arquitecto vicentino y los ilustra con algunas plantas de sus villas así como con la clasificación de los órdenes arquitectónicos, todo ello con escasa información útil a la hora de decorar el interior de la capilla del Carmen. A estas ilustraciones se añade un conjunto mucho más nutrido de estampas que, siempre sobre el tema de los órdenes columnarios, realizan una serie de variaciones sobre capiteles y aplicaciones de las columnas dentro de ricos marcos tardobarrocos. Muy diferente es Les ruynes de Palmyre, no concebido como un tratado sino como la explicación arqueológica de una ciudad tardoantigua por medio de la estampa. La evocación de las ruinas de Palmira aparece reflejada mediante hermosísimas planchas que captan visiones subjetivas de la ciudad, pero, junto a las vistas, se ofrecen verdaderas instantáneas fotográficas de algunos de los edificios mejor conservados cuya compleja decoración aparece descrita con la minuciosidad de un arqueólogo de la arquitectura. Será, sin duda, la imagen de las ruinas de Palmira, con su amplio abanico de molduras, casetones y tallas de todo tipo, la más útil para el decorador de una arquitectura que quiere ser planteada por su arquitecto, Vicente Gascó, como una vuelta al antiguo que destierre los devaneos de los ornamentistas barrocos. Así, en la Lámina VIII, Wood presenta un artesonado idéntico al empleado por Gascó en la Capilla del Carmen alternando los casetones octogonales con los elementos vegetales en los espacios entre ellos. En las láminas XV o XXIX se ofrece el capitel y entablamento de un orden corintio que parece ser la fuente de inspiración del utilizado en Valencia, con roleos vegetales en el friso y una cuidada y recargada molduración de las diferentes fajas de la cornisa. Y en las estampas que retratan los detalles decorativos se proporcionan, de manera casi literal, algunos de los motivos empleados en el interior académico, como los meandros y las guirnaldas mostrados en la lámina XVIII.

Las indicaciones dadas por Vicente Gascó fueron, bajo su supervisión, efectivamente seguidas en la ejecución material de la obra, y todo el interior de la capilla del Carmen rezuma de un refinado sentido decorativo de raíz tardoantigua. La planta oval, ensayada por Gascó en su proyecto no realizado para la capilla de San Vicente Ferrer en el convento de dominicos de la ciudad ${ }^{85}$ y aprehendida durante la intervención del arquitecto en la reforma de la basílica de la Virgen de los Desamparados ${ }^{86}$, adquiere carácter académico y antiquizante gracias a una particular aplicación de la ordenación y el adorno. En manos de Vicente Gascó la referencia a la arquitectura impresa se convertiría en una constante, y en 1792, casi veinte años después, con motivo de la renovación de la Catedral de Segorbe ${ }^{87}$, volvía a impo-

85 Archivo Municipal de Valencia (A.M.V.), Fondo Gascó, Dibujos 195 y 196.

${ }^{86}$ BÉRCHEZ, JOAQUÍN: «Basílica de Nuestra Señora de los Desamparados (Valencia)». En Monumentos de la Comunidad Valenciana. T. X. Valencia. Arquitectura religiosa. Valencia, Generalitat Valenciana, 1995, pp. 205-216.

87 BÉRCHEZ, JOAQUíN: La renovación ilustrada de la Catedral de Segorbe: del obispo Alonso Cano al arquitecto Vicente Gascó. Segorbe, 2001. 
ner el modelo de Les ruynes de Palmyre al que añadía La Conjuración de Catilina de Cayo Salustio.

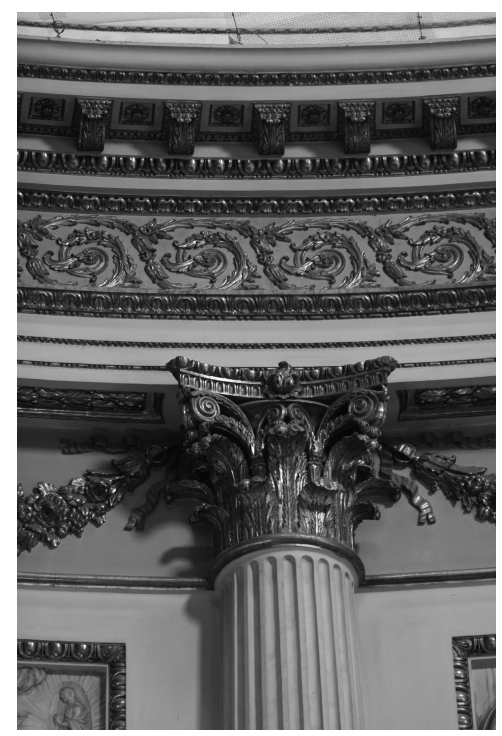

Figura 18. Vicente Gascó. Detalle del orden de la Capilla del Carmen en el convento homónimo, Valencia. Revestimiento decorativo iniciado en 1776. Fotografía del autor.

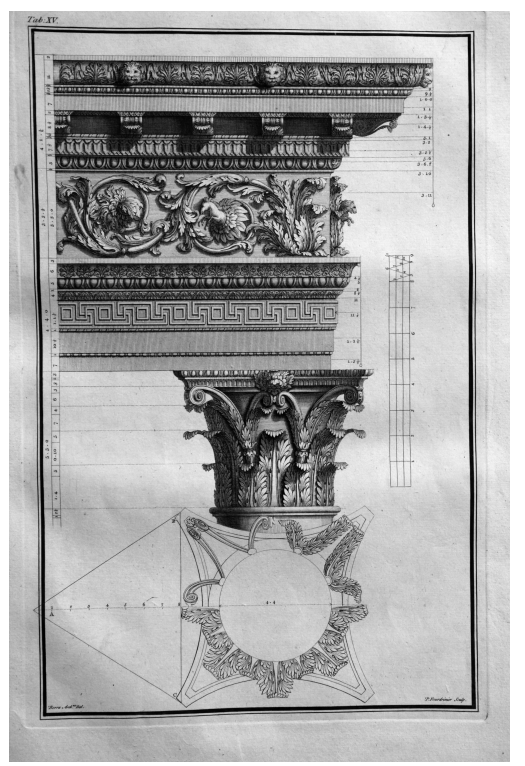

Figura 19. Lámina XV de WOOD, ROBERT: Les ruynes de Palmyre, autrement dite Tedmor, au desser. Londres, A. Millar, 1753. Biblioteca de la Real Academia de San Carlos de Valencia. Fotografía del autor. 
Los libros de arquitectura en la Valencia del siglo XVIII: de los modelos del Barroco...

La particular importancia de la arquitectura impresa y grabada en la configuración del ideario arquitectónico de la Real Academia de Bellas Artes de San Carlos se explica, básicamente, por dos factores coyunturales. Como se ha apuntado, en la gestación de los principios que animaron la Academia de San Fernando participaron no solamente los libros, sino también, y con mucho peso, por un lado la presencia en la corte de un Barroco cortesano de vocación clasicista activo en el seno de la institución a través de Giovanni Battista Sacchetti, Giacomo Bonavia o Giacomo Pavia, y por otro la posibilidad de los arquitectos de ser enviados a Italia. La combinación de estos tres elementos produjo un punto de partida distinto al valenciano y, también, una evolución diferente en la que tuvieron una importancia fundamental los arquitectos formados en Italia a la sombra de las corrientes teóricas del Neoclasicismo.

En Valencia la situación de partida de la que intentaron sustraerse los arquitectos académicos y, en particular, Vicente Gascó, era la de un Barroco de tintes mucho más autóctonos y gremiales. Una práctica de la arquitectura en la que el adorno, patrimonio de escultores y pintores, se encontraba profundamente arraigado en la sociedad. Por ello, cuando un arquitecto, Gascó, quiso cambiar los planteamientos de la teoría y la práctica de la arquitectura, sin pensiones en el extranjero, la única autoridad a la que pudo acogerse fue la de los libros. Del carácter libresco de las propuestas de Gascó, así como de la necesidad de diferenciarse de la práctica gremial, se desprende el radicalismo arqueológico de las tempranas propuestas del arquitecto, quien en 1762, cuando la Academia de San Fernando aún se encontraba en pleno proceso de evolución de sus concepciones en torno al hecho arquitectónico, presenta un modelo de basílica columnaria de un Neoclasicismo casi utópico. Sin embargo, la limitación del libro impreso como motor del cambio estético en el que se convertiría la Academia quedaría pronto a la vista en las obras efectivamente construidas por Gascó. El carácter novedoso y rupturista de las primeras propuestas del arquitecto valenciano con respecto a la práctica de la Academia de San Fernando se diluye conforme avanza el siglo, y así, mientras en Madrid, y fundamentalmente de la mano de Juan de Villanueva, se establecía un nuevo modelo de sobriedad casi neoática, en Valencia, en obras como la capilla del Carmen o la catedral de Segorbe, se enquistaba una arquitectura cuyas ordenación y decoración interiores repetían la inspiración en las mismas estampas. Unas ordenaciones riquísimas, cuajadas de dorados, guirnaldas y molduras que, pese a su inspiración directa en los modelos de la antigüedad, distaban mucho de ser neoclásicas y se convertían en un hito más que marcaba la importancia del libro en la arquitectura valenciana del siglo XVIII. 
Cap09 14/11/2011 13:23 Página 220

- 